Queering South Mississippi: Simple and Seemingly Impossible Work

Kamden K. Strunk

Auburn University; Research Initiative on Social Justice and Equity

Douglas R. Bristol

The University of Southern Mississippi

William C. Takewell

Millsaps College; Research Initiative on Social Justice and Equity

NOTICE: This is the authors' version of a work that was accepted for publication in Educators queering academia: Critical memoirs. Changes resulting from the publication process, such as peer review, editing, corrections, structural formatting, and other quality control mechanisms may not be reflected in this document. Changes may not have been made to this work since it was submitted for publication. This article may not exactly replicate the final published version. A definitive version was subsequently published in sj Miller \& N. M. Rodriguez (Eds.), Educator queering academic: Critical memoirs (ISBN 978-1-4539-1877-7). 


\section{Queering South Mississippi: Simple and Seemingly Impossible Work}

Our purpose in writing this is to recount and analyze the push for queer-positive policy at The University of Southern Mississippi (USM) over the past several years, understanding the spaces that opened for such work, and why such spaces rapidly open and close on the USM campus. We cannot begin to tell the story of our experience working for queer-positive programming and spaces, and the challenges we have encountered in that work, without first contextualizing that work within the institution of The University of Southern Mississippi, the system in which it exists, and the state of Mississippi. The University of Southern Mississippi, founded in 1910, hovers near the 15,000 mark in enrollment, and has campuses in Hattiesburg, MS and Long Beach, MS, plus some small research sites along the Gulf Coast. It, like many in Mississippi, has constant budget shortfalls, and a cycle of enrollment/financial emergencies, while struggling to find consistent quality of students and enrollment numbers. It exists in a system that places it alongside the University of Mississippi (Ole Miss) and Mississippi State University for budgeting and evaluation purposes, an unfortunate reality many years.

Forces against change and progress can be particularly salient in the Deep South, where calls to tradition, appeals to faith, and staunch opposition to federal intervention and outside meddling in local affairs are hallmarks of how policy is made (Crespino, 2007; Shoreman \& Haenn, 2009). Mississippi can, in some ways, be thought of as emblematic of the Deep South, with its strong history of suppressing of civil rights (Bolton, 2005), its perennially poor outcomes in education (Education Week Research Center, 2014), healthcare (CDC, 2013), and quality of life (U.S. Census Bureau, 2013), not to mention its current work to suppress the legal rights of LGBTQ citizens. Anti-LGBTQ measures have been popular with the state's voters, who approved a 2004 constitutional amendment banning same-sex marriage by a margin of more than 
80\%. Mississippi politicians continue to promote anti-LGBTQ measures. In February of 2014, Congressman Steven Palazzo publicly criticized same-sex marriages performed on the television broadcast of the Grammy Awards (Associated Press, 2014, Nov. 28), an action resulting in some of the first organized LGBTQ activism in the area in recent years. In November of 2014, Governor Phil Bryant appealed the ruling of a federal judge that overturned the ban on same-sex marriage (Clarion-Ledger, 2014, Feb. 6), and following the U.S. Supreme Court ruling in June of 2015, the same Governor Bryant attempted to resist implementing the ruling in Mississippi, even to the disagreement of the state's Attorney General (MacNeal, 2015, July 1).

The University of Southern Mississippi (USM), where we have worked for several years to create queer-positive policy and spaces, $9 \%$ of students identify on the LGBTQ spectrum (Strunk, Suggs, \& Thompson, 2015). At USM, LGBTQ students are nearly twice as likely to experience some form of harassment or victimization on campus, are less comfortable on campus, hear disparaging comments from staff, administrators, and other students more frequently, and witness threatening behavior more commonly. In fact, over half of LGBTQ students at USM hear disparaging comments about sexual orientation frequently on campus, and a little less than one in four have witnessed threatening behavior on the basis of sexual orientation on campus (Strunk, Suggs, \& Thompson, 2015). Yet, while these numbers are part of telling a story of an environment in desperate need of queer-positive policy and spaces, they also show some of the work we have done in the past few years in their mere availability.

Our experiences, as narrated in this critical memoir, with opening spaces for queerpositive work and policy at The University of Southern Mississippi begin in the Fall of 2013. It is worth noting some queer-positive space existed on campus prior to that time. For example, a small gay-straight alliance had existed on the campus since the late 1980s. Also worth noting 
was that senior administrators attended the opening meeting of that group, and considered it an adequate intervention to meet the needs of LGBTQ students up until the Fall of 2013 when a number of forces converged to change that perception, including faculty pressure, changes in federal Title IX guidance, the rapid pace of change in public opinion, and the shifting legal landscape for LGBTQ rights.

\section{The Accidental Activist on the Gulf Coast Campus: Catalyzing Change}

We begin with the story of an 'accidental activist' in Douglas Bristol, an author of this piece and tenured associate professor of history on the USM Gulf Coast campus in Long Beach, MS. One example of space opening for queer-positive work at USM is the Alliance for Equality, a student organization established in the fall of 2013 on the Gulf Coast campus in Long Beach, Mississippi. To provide a framework for understanding this nascent LGBTQ equality movement, the following discussion refers to the model of movement emergence that political scientist McAdam (1982) used to examine the African American Civil Rights Movement in Mississippi during the 1960s. McAdam emphasizes three crucial factors: expanded political opportunities, the degree of organizational readiness within the minority community, and the liberation of consciousness. All three were present to some degree on the Gulf Coast campus of USM.

Having an out lesbian Vice President in charge of the campus presented an opportunity that had not existed before. Progressive-minded faculty and staff members had already formed a resilient support network, which facilitated recruiting people for an LGBTQ Equality movement. Although Douglas Bristol was out and had tenure, he became an activist accidentally when a younger straight colleague in his support network asked him why there were no programs or student groups for LGBTQ students. The pair met with the Vice-President, and plans were made to hold the LGBTQ Safe Space (known at USM as ALLIES) training program on the Gulf Coast 
campus in September of 2013. Because this training had not been held for years on the Coast and because the Vice President invited all faculty and staff to attend, the training ran out of space at seventy people. The big turn out and related publicity sparked a cognitive liberation. LGBTQ faculty, staff, and student realized they had allies on campus. The impact of the experience was particularly noticeable in students.

The training gave students a new sense of optimism about what was possible. For many students, this was the first time they had ever heard administrators, faculty, and staff talk about LGBTQ students in a Mississippi school, and the discussion focused on helping them. The ALLIES training coincided with a wave of positive news about same-sex marriage in national media. Together, this event and the news made a core group of students believe it was possible to make USM a more tolerant university. Several LGBTQ students met with Bristol and asked him to help them establish an LGBTQ student organization, which the students named the Alliance for Equality. At the Student Government meeting that officially recognized the organization in November, Alliance student leaders were asked to explain how the group would help students who were not gay. One of them said, "I am not gay, and I am an evangelical Christian. I am unsure about the morality of homosexuality. But I know my church teaches me it is not our place to judge others, and I know I love my gay sister. I want her to feel welcome wherever she goes. There are other allies like me on campus." The young evangelical demonstrated his belief that he would change things for the better if he spoke out on behalf of his sister.

The LGBTQ Equality movement on the Gulf Coast campus has waxed and waned since the founding of the Alliance for Equality. Once again McAdam's (1982) work points to two factors that seem to explain the outcome: the institutional response to a reform movement and the maintenance of a shared consciousness. The institutional response was largely positive. 
Because there were no organizations for minority students on the Gulf Coast campus and few student organizations in general, the Alliance for Equality had little competition when it sought help and resources from the campus staff. The Division of Student Affairs organized, for the first time, a Diversity Week and a Civility Week that had programs devoted to LGBTQ students. It also awarded the Alliance for Equality the Student Organization of the Year Award for 20142015. Campus officials represent just one side of the coin however. McAdam argues that the institution's response is also influenced by strength of the insurgent group wanting change, which varied on the Gulf Coast campus. The monthly Alliance events consistently drew twenty to thirty people, and the Annual Smile for Equality picnic had more than seventy-five people two years in a row. On the other hand, there was constant turnover in the student leaders of the Alliance who felt overburdened with responsibility because few students would help run the organization. McAdam contends that organizational issues pose a dilemma for social reform movements because they lose their grass-roots followers. Because the university tied support to maintaining a well-run student organization, organizational issues became the priority of student leaders and the faculty advisor. Yet students had more immediate concerns than attending workshops for student leaders. They wanted LGBTQ problems addressed. Moreover, there were limits to how committed students were to seeking change. For some, just attending workshops represented too big of an outing, leading them to drop out of the Alliance. Concurrently to these developments on the smaller Gulf Coast campus were developments on the main Hattiesburg campus. Central to these openings for queer-positive work was the Vice President for Student Affairs at the time. He was first contacted in the summer of 2014 by Douglas Bristol, who was working with six faculty colleagues to get USM to join the Campus Pride Index, which rates how LGBTQ-friendly the policies and programs of more than 450 participating universities are. The 
departure of the Vice President of the Gulf Coast had been mired in controversy, and she had been a strong advocate for LGBTQ students. As a result, Bristol, along with colleagues on the Hattiesburg campus turned to the Vice President for Student Affairs to work for change at USM. Bristol and a lesbian faculty colleague met with the Vice President in the summer of 2014. Although the Vice President said he was open to a process of incremental change based on meeting a national standard, he would not commit to working to get USM to participate in the Campus Pride Index. By way of explanation, he pointed out that USM had had a Gay-Straight Alliance on the Hattiesburg campus since 1986. He had attended the first meeting of that group and made positive comments, which found their way into the student newspaper. Then, a state legislator had copies of the article distributed to every member of the Mississippi legislature. The Vice President was vague about the repercussions of these developments, but he told the story as if it were a cautionary tale. This senior administrator made it clear that he feared a political backlash over the controversial subject of LGBTQ students.

\section{The Queer Quantitative Methodologist: Bringing Data, and Frustration}

Our story of queer-positive work continues through the perspective of Kamden Strunk, another author of this work who was, from May of 2013 through May of 2015, an assistant professor of educational studies and research on the main Hattiesburg Campus of USM, and is a director of the Research Initiative on Social Justice and Equity (RISE). This pairing placed Kamden in the position of regularly engaging in queer research and advocacy, especially in Mississippi and regionally. Following developments with Douglas Bristol and his interactions with the Vice President for Student Affairs, the Vice President subsequently met with the LGBTQ student organizations on both campuses of the university, with interested faculty, funded an LGBTQ scholarship, agreed to provide additional training for campus police, and to 
appoint a commission to redesign the campus ALLIES program and make policy recommendations. One pivotal moment, in our estimation, in opening some space for these conversations was a meeting early in the Fall of 2014. During this meeting, the Vice President asked Kamden Strunk to attend to have the perspective of a researcher. Through the course of this conversation, the idea of a campus climate survey was hatched among the group. The same administrator would later tell other faculty (whom he was apparently unaware were acquainted with us) that he felt confident the survey would show the climate was essentially positive and affirming for LGBTQ students - that there was no problem. In our report of those survey results, from which we selected the above-reported findings, we found deep problems (Strunk \& Suggs, 2014). Nevertheless, it was at that meeting that the administrator asked us to complete a campus climate survey to evaluate whether intervention was necessary and to what extent change was needed in policy and practice. That campus climate survey became a necessary leverage point for further conversations - what the administrator apparently believed would be a way to dissuade our attempts to work for queer-positive policy became a way to persuade him and others of the need. This led to faculty senate resolutions calling for action to improve the climate for LGBTQ students (Gulf Coast Senate, 2014; Faculty Senate, 2015).

This work was not without frustration. In fact, after the publication of the final study report in 2015, one particular USM administrator made attempts to discredit the results of the survey. This was initially through contacting the Institutional Review Board to ask them to investigate the ethics of the climate study. When this failed, the administrator moved to directly contacting co-authors of the report, who had provided expertise in introductory sections of the report. The administrator further contacted Kamden Strunk on multiple occasions in apparent attempts to gain inappropriate access to identified data, contact information for participants, and 
to request contact information for people who had received the report (which was impossible as it had been distributed by the Faculty Senate to all faculty). Nevertheless, the report was public, accessible to all, and on the USM website. Some action was necessary - the Vice President for Student Affairs, who was at least superficially supportive throughout, appointed a commission to examine training programs such as ALLIES as his solution.

\section{The Student Affairs Staffer: Working Within the System}

We tell the next portion of this story through the perspective of William Takewell, who for several years worked in the Division of Student Affairs at USM, and was employed there throughout this period. William was a member of the Vice President's commission on LGBTQ initiatives, which had specific responsibility for analyzing and improving the university's ALLIES training, included faculty and staff from across the institution representing a variety of academic departments and functional areas of student affairs. The task force also included two authors of this chapter. Most of the members of the task force felt comfortable identifying openly as either a member of the LGBTQ community, or as an ally to the community. The task force worked to establish what the needs were on campus for the ALLIES training program by including students from the campus' Gay Straight Alliance on the task force, and discussing openly with them what they felt the campus was lacking in regards to LGBTQ+ inclusivity. The meetings of the task force occurred in tandem with the faculty-led campus climate survey to assess the experiences of LGBTQ individuals. Of important note is that at the time the climate survey was issued and the task force assembled, there was no administrative office, support person, or official LGBTQ+ initiatives available on the USM campus for students, staff, or faculty. While an ALLIES training program was available, the program began a review process in November of 2014 to assess the effectiveness and accuracy of the program. These 
recommendations were informed by the campus climate survey (Strunk \& Suggs, 2014; Strunk, Suggs, \& Thompson, 2015), and also from the task force's interactions with LGBTQ+ students who were able to attend the gatherings of the task force. Recommendations included revising the mission statement of the ALLIES program, creating two 'levels' of the training - one for incoming students and employees, and one for those wishing to become allies/advocates, finding a permanent 'home' for the training within Student Affairs, and creating a plan for ongoing success of the program, among other suggestions.

The task force offered up its recommendations in late April of 2015. However, the 20142015 school year included multiple changes to the landscape at USM: A financial crisis calling for large across-the-board budget cuts emerged due to declining enrollments, the Vice President for Student Affairs announced his retirement, and for a number of reasons several faculty working on queer-positive policy proposals left the university. Since the task force offered these recommendations, there has been a lack of communication as to what will happen next for the ALLIES Program and for LGBTQ+ issues on campus. Transitions in key faculty, staff, and administrators likely explain some of this lack of movement. It parallels a lack of movement on other initiatives which, at one point, seemed inevitable. One example is conversations that began about trans-inclusive housing policies. These seemed inevitable and simple in the Spring of 2014, but going into the Summer of 2015, they seemed a distant hope unlikely to materialize. However, there are some positive changes as a direct result of the task force's work and the publicity of the campus climate survey. Students seem to be more aware of what is going on with campus in regard to the issues of diversity and multiculturalism, and there has been interest shown by a variety of students to establish programming and initiatives that are inclusive and protective of all students. 


\section{What Happened? An Analysis of Institutional Responses to Queer-Positive Policy Work}

Our analysis, in looking back at the past years of working for queer-positive policy at USM, is that many of the challenges which are supposed to explain why reforms were not enacted seem to be illusory. While budget shortfalls at the institution were all too real (and remain a threat to the institution on an ongoing basis), the reality is that the majority of the reforms called for would not have cost money at all. One example is our strong and insistent suggestion that housing policies for trans* students be written down and made accessible to prospective and current students online. Student Affairs has a standard way of working with such students, so no new policy would be made, but merely working policy would be written down. And the cost of the paper to write it on or the server space to put it online is surely not the objection. Others that we asked for would cost extremely small amounts of money - a notion often met with questions about which student groups such funds might be 'taken from'. We tend to reject the idea that a $\$ 500$ program across an institution with an annual budget of $\$ 278.7$ million for 2015 (USM, 2015) would be unsustainable or would require cuts to programs for students of color, as seems to be the implication. Instead, we suggest that two forces are at work in these institutional tactics to avoid queer-positive policy work: 1) Institutions can, by putting the interests of marginalized groups against each other, diffuse the energy and activism that would otherwise be behind a single policy push. In other words, when faculty who might be for queer-positive policy learn that its enactment would (somehow) lead to less resources for women or students of color, some are likely to lose interest in that policy fight. Even though such dichotomies are likely false, they are powerful in diffusing the interests of people who are otherwise interested in such changes. 2) As the Vice President for Student Affairs suggested in his meetings with us, institutions subject to extremely conservative legislatures may look for 
ways 'out of' doing queer-positive work. The Vice President at USM referred to a fear of "going too far" and "catching attention" of legislators. In other states, such attention has not been good for colleges. In one example, South Carolina legislators cut funding to two institutions because they assigned readings viewed as queer-positive (Kellogg, 2014, February 28). In an environment where funding is scarce and cuts constant, such attention can truly be devastating to the institution.

We write this today from an interesting position. While all authors of this piece were at USM working for queer-positive policy over a period of years, today only one of us remains at the institution. Looking back, we are left to wonder how, what seemed so simple at our initial meetings with administrators became so complex and seemingly impossible: creating some meaningful queer-positive student policies. The institutional response was in some ways typical: We need more time. We need more data. We don't have the money. We don't have the legislative support. Yet, in other ways, the institution seems to have inadvertently set a path for itself that will be difficult to undo. The data, now public, available online, on the institution's own website, led to faculty senate resolutions calling on the President to act. Next year, they plan more research (by an outside firm instead of by faculty researchers), perhaps to buy more time before any real action, perhaps hoping for better outcomes from different data.

In general, we view three cooperative forces as being at work in institutional responses to our work for queer-positive policy at USM: 1) There is a general institutional resistance to change, particularly in the South, and even more so in Mississippi. 2) As evidenced in statements by the Vice President for Student Affairs and other administrators, there is a real and valid fear of 'going too far' with queer-positive policy work. This fear is rooted in legislative reprisal for being too easy on 'gays' and the 'gay agenda'. This is evident in the Vice President's anecdote 
about the newspaper with quotes from him about the Gay Straight Alliance being on the desk of every state legislator, and recent efforts in South Carolina to cut funding to colleges perceived as too gay-friendly. 3) These two instincts lead colleges to play a zero-sum game in which the pit marginalized groups against each other to fight for small amounts of funding. This, quite naturally, diffuses the energy to work for policy that benefits diversity and campuses that embrace and welcome all, as students and faculty are forced to choose who to support.

While recognizing these as the reality in which we work and exist, and that administrators and policymakers are embodied beings who take on the expectations that saturate the culture around them, we reject these dialogues. We know that colleges can fund initiatives that benefit women, students of color, students with disabilities, and LGBTQ students, particularly when such initiatives are so inexpensive, and often free. We know that there are ways to work with legislators, even in religiously and politically conservative environments, instead of around them to work for student recruitment, persistence, and success, instead of denigrating, ignoring, and marginalizing some students. We call on administrators, faculty, staff, and students to be bold in working for queer-positive policy while being attentive to ensuring all students are welcome, safe, and successful, and brave in explaining and advocating for that work with their boards and legislators. 


\section{References}

Associated Press. (2014, Nov. 28) "Mississippi Appeals Ruling in Same-Sex Marriage Case," Jackson Clarion-Ledger. Retrieved from http://www.clarionledger.com/story/news/2014/ 11/28/mississippi-appeals-ruling-in-gay-marriage-case/19627297/

Centers for Disease Control and Prevention. (2013). Statistics of the state of Mississippi. Retrieved from http://www.cdc.gov/nchs/pressroom/states/MS_2013.pdf.

Clarion-Ledger. (2014, Feb. 6) "LGBT activists protest at Congressman Steve Palazzo's Office," Jackson Clarion Ledger Retrieved from http://archive.clarionledger.com/ article/20140206/NEWS/140206013/LGBT-activists-protest-Congressman-StevePalazzo-s-office

Crespino, J. (2007). In search of another country: Mississippi and the conservative counterrevolution. Princeton, NJ: Princeton University Press.

Education Week Research Center (2014). Mississippi state highlights 2014: District disruption and revival: School systems reshape to compete and improve: A special supplement to Education Week's quality counts 2014. Retrieved from Education Week's website: http://www.edweek.org/media/ew/qc/2014/shr/16shr.ms.h33.pdf.

MacNeal, C. (2015, July 1). "Mississippi AG asks to stop defending guv in gay marriage case." Talking Points Memo. Retrieved from http://talkingpointsmemo.com/livewire/jim-hoodphil-bryant-mississippi-gay-marriage

McAdam, D. (1982). Political Process and the Development of Black Insurgency, 1930-1970. University of Chicago Press.

Shoreman, E. E., \& Haenn, N. (2009). Regulation, conservation, and collaboration: Ecological anthropology in the Mississippi delta. Human Ecology, 37, 95-107. 
University of Southern Mississippi. (2015). Summary of revenues and expenditures. Retrieved from http://www.usm.edu/sites/default/files/groups/office-fiscal-planning-andanalysis/pdf/summary_of_general_and_auxiliary_fund_revenues_and_expenditures_201 5.pdf

U.S. Census Bureau. (2013a). Poverty: 2000 to 2012. American Community Survey Briefs. Retrieved from http://www.census.gov/prod/2013pubs/acsbr12-01.pdf. 